\title{
Space-Places and Third Teacher: The Issue of Architectural Space in the Age of Knowledge Cities and Schools 3.0
}

\author{
Laura Anna Pezzetti
}

\begin{abstract}
Information and knowledge are not synonyms; rather they are quite distinct facts. As a form of knowing never separated from the critical processing of subjects, knowledge is sensitive to space. The city as a knowledge hub demands a dense exchange of context where urban morphologies cannot be replaced by dispersed relations allowed by ICT networks and smart efficiency. Symmetrically in school buildings, that is, the basis of knowledge infrastructures, learning architecture is not replaceable by an unstructured environment, mechanically derived from a new flexibility allowed by digital technologies and specific mainstream views on "innovative teaching". This paper critically explores the role of architectural space in the age of 2.0-3.0 schools, discussing the relationship between transformations introduced by the unstructured classroom upgraded by digital technologies and new necessary experimentations on architectural space, the third teacher. Architectural space is not only an active player in influencing learning and development but is also a constitutive element in the formation of thought and a specific tool of critical, cultural and imaginative knowledge of reality. Organising space means organising the metaphor of knowledge.
\end{abstract}

Keywords Knowledge cities $\cdot$ School buildings architecture $\cdot$ Learning spaces • Third teacher

\section{The City and School Building as Learning Spaces}

In the century defined as the "century of knowledge" (Drucker 1968, 1997), the development and sharing of knowledge is said to be the driving force of Europe's economic competitiveness. Within the new economic, social and urban paradigm, the concept of cities as knowledge hubs has been consolidated as a desirable future for European cities (Lisbon Strategy 2000; European Year of Creativity and Innovation

\footnotetext{
L. A. Pezzetti (ه)

Architecture, Built Environment and Construction Engineering-ABC Department,

Politecnico di Milano, Milan, Italy

e-mail: laura.pezzetti@polimi.it 
2009). ${ }^{1}$ While in the 1990 s many economists and a number of planners considered the city a residue of the industrial era, surpassed by the "erasing geography through technology" (Koolhaas 1994) or "the annihilation of space through time" (Harvey 1988), that is, by the indifference to locations favoured by networks, the knowledge economy considers the city as a physical place and the privileged context of exchange.

It is within the complexity of urban systems that knowledge is processed and disseminated; innovations, culture and creativity are produced (Florida 2002); talents are developed and accessibility to global economies is focussed on (van Winden 2010; Yigitcanlar 2007; Franz cir. in Yigitcanlar et al. 2008). It is in cities as well that universities, the true infrastructures of knowledge, find consolidation and development.

Information and knowledge are definitely not synonyms, but quite distinct facts. As a form of knowing never separated from critical elaboration, knowledge is sensitive to physical distance and demands a physical and dense exchange context: space, which is not replaceable by dispersed relations of ICT networks and Smart City technologies. The objective of a knowledge city is to promote the development, sharing and dissemination of knowledge by enhancing relationships, intersections and porosity between the various functional urban systems and, within these, between different fields and competences (Pezzetti 2012a, b). Specialisation and self-segregation do not correspond to the cross-sectoral and creative contamination on which innovation is based, as well as stiff boundaries between disciplines; they instead, today, constitute an obstacle to scientific research.

Cities themselves must be redesigned as knowledge hubs - that is "purposefully designed to encourage the nurturing of knowledge" according to Leif Edvinsson (2003 cit. in Dvir and Pasher 2004), a leading expert on intellectual capital-distinguishing not only for their ability in clustering innovation, creativity and research, but also for the opportunity of self-realisation and development offered to their citizens and the creative potential and resilience of the communities established.

Since the century of knowledge is not reduced to the "century of information", it will be necessary to also include in this horizon the context of exchange, critically rethinking the efficiency of Smart Cities (so free of hindrances and managed by big technological companies) and the role and culture belonging to physical, built and urban space (Pezzetti 2012a, b).

Aspects that are the basis of creative innovation such as serendipity, culture and community are also at the basis of urban life and challenge the rational deterministic approach to innovation itself.

The reorganisation of the city and its functional systems should entail innovative concepts of urban design and experimentation on new prototypes of learning spaces, which are key tools to achieve this aim.

\footnotetext{
${ }^{1}$ Starting from the Lisbon Strategy (2000) and more recently with the European Year of Creativity and Innovation (2009), the European Council has recognised knowledge and culture as catalysts of innovation and creativity. Cultural activities and the creative industries were thus recognised as potential for economic innovation and for individual and social development.
} 
Demanding creative connections between the functional systems and the assets present in a given context, the characteristics of a knowledge society could finally reverse the tendency to build the city through mono-functional enclosures and isolated objects, boosting the role of urban morphologies as a continuous system of urban and spatial relationships. On the other hand, learning building needs to extend the regime of collective activities encouraging their integration and contamination with the urban structure.

The role of the city as the place, where knowledge concentrates and is transmitted, is inherent to the very origin of the European city, from the gymnasia of the Hellenistic cities to the cathedral schools of the revived medieval urban communities, and to the emancipation of universitas and the institutionalisation of compulsory and higher education as an indispensable guarantor of modern industrial development. Just as a certain degree of concentration and integration of multiple functions is inherent to the early places devoted to education, or the leading role they played in questioning consolidated schemes of knowledge and mentality.

The early type of Hellenistic gymnasium, for instance, showed a dynamic relationship between the introvert microcosm of its colonnaded peristyle and its opening to the whole city, as well as the integration of different activities: from the study plan that put literary, philosophical and grammatical knowledge on the same plane as physical education-which was the original purpose, to the simultaneous presence of lessons, conferences and banquets. The integration of the baths, in Roman times, juxtaposed the simple xystus system-the covered portico of the Hellenistic gymnasium - with an elaborate series of rooms, giving thus rise to the idea of inner space (Pezzetti 2016).

The challenge of the knowledge society evidently invests schools of every grade, which are "knowledge infrastructures" themselves since they form, pass down and certify knowledge, and because in turn they employ knowledge workers while integrating innovative forms of transmitting knowledge, by working in network with other schools and other social players.

Only in recent years, however, supporting the knowledge culture has been understood as investing in education at all levels, starting from the founding substrate of primary schools, while also stressing that only a country of educated people can move towards sustainable development (De Maio 2011).

Spread countrywide, school buildings constitute not only poles of education but also the resources around which the civic dimension of society condenses. Hence, it becomes important to consolidate their "second life", extending their fruition beyond the teaching time and turning them into civic centres, poles of reference for local neighbourhoods and in a network with the territory, no longer dedicated exclusively to ordinary learning but also educational, recreational, cultural and cooperative activities targeting a wider audience.

Creatively circulating the culture of places together with that of knowledge institutions cannot overlook the design of these places as a constructed idea. It is not merely about regulating and making school buildings safe, adapting them to educational changes or improving their "performance". It is about integrally transforming improper buildings or banal containers that are the fruit of prefabrication logic, 
entirely redesigning the built environment or, if impossible, converting it to other functions and replacing it with real knowledge architecture. ${ }^{2}$

Schools need to become hubs for lifelong learning, stimulating places not only for students but also for adults, teachers and staff, hosting hybrid spaces to produce, exchange and disseminate culture, while opening up to the outside, to the neighbourhood and the city. The innovation of the concept of classroom and collective spaces themselves must be able to encourage this change. The architectural space must return to be a further pedagogical tool. As Rogers wrote back in Rogers (1947) "If a sacrifice is imposed, no budget item is better justified" (Rogers 1953).

The current crisis places European cities and their economies in a state of transition. A condition which, according to Hall (2010), already proved to be favourable to cultural creativity and to the transition towards new and unexplored ways of organisation. ${ }^{3}$

\section{Space-Places and Commonplaces. The Issue of Architectural Space in the Era of 2.0-3.0 Schools}

If we aim to foster settlement systems as knowledge hubs according to a culturally broad sense, one that is also contextually specified, then instead of following acritically up-to-date planning clichés (creative cities, science cities, smart cities, etc.) or programmes delegating innovation essentially to the collaborative sharing of the 2.0-3.0 web information, we should launch an approach that is in itself creative, experimental and multidisciplinary. A renewed attention to the educational character of space itself is needed, since space is the third teacher (Malaguzzi) ${ }^{4}$ : organising space means organising the metaphor of knowledge.

Just as the knowledge city is not a spatially neutral phenomenon, knowledge buildings cannot disregard the knowledge intrinsic in architecture as a specific way of critical, cultural and imaginative knowledge of reality.

\footnotetext{
${ }^{2}$ According to the data provided by the Italian Ministry of Public Education, authorised school buildings in Italy amount to more than 42,000 (42,292), of which 33,825 are operational. Of these, $55 \%$ were built before 1976 , and only $70 \%$ were built specifically for use in the education sector.

3"An entirely different, historically-based approach came from the present author in a study of six 'creative cities' in Hall (1998): Athens in the fifth century BC; Renaissance Florence; Shakespearean London; Vienna in the eighteenth and nineteenth centuries; Paris between 1870 and 1910; and Berlin in the 1920s. The first three of these cities became culturally creative long before they proved very adept either at technological advance, or in managing themselves effectively. All enjoyed golden ages even while the majority of their citizens laboured in abject poverty, and even while most people lived in conditions of abject squalor — at least, by today's standards" (Hall 2010).

${ }^{4}$ According to the educationalist Loris Malaguzzi, who in the WWII aftermath was the founder of the Reggio Emilia educational system, known throughout the world as the "Reggio Approach", children have three educators: adults, other children and the physical environment they are immersed in. The concept of the "third teacher" was recently resumed in O'Donnell WP, Peterson BM et al., The Third Teacher (2010).
} 
With regards to school buildings, the issue was already clear to Ernesto Nathan Rogers back in 1947 when, complaining about the continual cuts in education's budgets, in an editorial for the magazine Casabella he declared that progressive pedagogy could not ignore its architectural dimension, since "the problems of education cannot be accomplished without a learning architecture" (Rogers 1947).

Architectural space is not only an active player in influencing learning and development. Since architecture is a language — while the vague and indeterminate concept of "environment" is not, architectural space is a constitutive element of the formation of thought: "Beautiful schools are good schools" (Rogers 1953).

New forms of teaching geared towards working individually, in groups or in workshops, to supplement traditional face-to-face teaching, require layouts of greater spatial complexity in school buildings, while at the same time allowing their evolution over time.

To stimulate conditions for multiple forms of learning, integrating the classroom with the school and the school with the community-while also tackling the challenge of a multicultural population and transformations in employment- the new schools neither will be confined to simply unstructuring the organisation of previous types nor stifling the challenges linked to the emergence of digital technologies by unstructuring teaching into modular multipurpose environments equipped with multimedia support while remaining substantially conventional in the poverty of their spatial qualities. ${ }^{5}$

Although early innovative cooperative theories and accomplishments were established after World War II by the Italian experience of the "Reggio Approach" led by Loris Malaguzzi, which have been and still are considered worldwide (Gandini and Gambretti 1997; Edwards et al. 2011) to be a leading reference ${ }^{6}$ for the emphasis they place on creating beautiful environments to support children's emotional, cognitive and social development (the "challenging" and "creative" child, i.e. the future active citizen of the city), the difficulties of the educational system in understanding the need to give innovative teaching a consistent architecture emerge clearly.

Shifting from learning environment to learning architecture, some challenges, simplifications and contradictions appears.

In an interview I carried out in 2015, Herman Hertzberger while discussing the school built at Romanina outlined the distance between innovative educational approaches and the acceptance of real spatial innovations, which affected the design.

\footnotetext{
${ }^{5}$ The flexible learning spaces promoted by "Future Classroom Labs" by European Schoolnet are in fact substantially devoid of formal and architectural connotations, focusing solely on functional flexible aggregation of environments, modular furnishing and introduction 2.0-3.0 equipment. See Bannister (2017), Guidelines on Exploring and Adapting Learning Spaces in Schools; Mosa (2013), "Nuovi spazi per l'apprendimento", https://www.insegnantiduepuntozero. files.wordpress.com/2013/07/quandolospazioinsegna.pdf; the teaching model "without partitions and classrooms" like Vittra Telefonplan (2011) in Stockholm, assumed as a model in http://www. indire.it/quandolospazioinsegna/scuole/vittra.

${ }^{6}$ In 1991, the "Newsweek" devoted an article to the "Reggio Approach" describing it as the best educational system in the world.
} 
Despite Italy's “New Guidelines” (MIUR 2013) have substituted quantitative regulations with performance standards, foreseeing five space-types (agorà, classroom, workshop, individual and informal space), the programme "Scuole Innovative" (2016) has failed to coordinate coherently the competition programme since most pilot projects required incoherent dimensioning of learning spaces based on previous legislation standards and related educational models.

Innovative programmes for school building design are an international trend but few EU countries have promoted it in a strategic and coordinated way, among which are the UK (BSF), Netherlands, Portugal (Parque Escolar) and Denmark (SKUB), although with different outcomes in architectural quality. The Danish SKUB "The School of the Future" (1998-2010), developed in Gentofte's municipality-where the milestone Munkegård School, designed by Jacobsen in 1956 was built—brought to the construction of the celebrated Hellerup School (2002), a "school-container" that repeats some themes developed by Hertzberger's schools although inserting them in an open plan. Even more extreme is the open plan of Ørestad Gymnasium (3XN 2007), a mega-block allowing for teaching and learning decks that overlap and interact with no distinct borders, the latter being perceived as obstacles to the fluidity of multidisciplinary interaction.

If those cases still rely on design, the overcoming of the classroom-based layout mostly relies on modular environments (e.g. Epping View Primary, Melbourne, 2009) then obviating the banality of the "container" by the upgraded design of sectional furnishing. Modularity and open space appear as easy shortcuts compared to questioning how to overcome the classroom/corridor opposition by granting the former a more permeable configuration and to the connecting spaces the value as a collective classroom, square or Learning Street, thus enabling students to explore different degrees of self-responsibility and self-learning possibilities.

Flexibility and multifunctional spaces in architecture - for example the schools by Canella and Hertzberger shown in different ways - are not necessarily synonymous with modularity and uniformity, namely the absence of architectural character as these concepts, already explored by manuals from the 1960s, and which subsequently failed, usually entail.

Should the school be just an "explicit rendition of the latest theoretical theories" as Dudek's book (2000) maintains?

Flipped classroom, digital teaching, IWB or BYOD are some of the practices derived from the UK and the United States that are taking foot in the EU, which see the alliance between the use of new technologies and active education focussed on the learner rather than on the teacher and on competences rather than on transmitted knowledge, not without raising some actual questioning on the theoretical weakness of their fundamentals. ${ }^{7}$

The challenges of digital technologies have produced the new cliché of 2.0-3.0 schools (soon 4.0), where the instance of the active participation of students seems to focus on interaction with the technological fetish-object, whether it be an IWB

\footnotetext{
${ }^{7}$ A petition against competency-based teaching was launched in 2018 in Italy, gathering a large number of people, professors and intellectuals.
} 
or a tablet (BYOD), almost as if the content is guaranteed to the learner by the collaborative use of the medium - "the medium is the message", as the essay by McLuhan back in $1967 .{ }^{8}$ Or as if knowledge could coincide with information, or the experience of space with that of a nomad who wanders from workshop to workshop with a tablet underarm.

The tactile and dynamic exploration of physical space, the manner in which the activities are structured, and the boundaries between individual and collective space seem to give way to the seduction (and overestimation) of a virtual reality that is simulated, and soon, perhaps, augmented; in any case dislocated and surrogate, to be experienced in a "halted motionless" vision inside a "container" that is spatially indifferent and undifferentiated.

Cooperative learning, it is said, "unstructures" the entire school, thus justifying the informal space with the revolution brought about by the ICT technological devices. However, if the various areas lose their distinctive character and everything becomes unstructured and indefinite, there is no longer much left to explore, exchange or recognise (Hertzberger 2008).

Form and thought are linked. The open plan, where all spaces and boundaries become blurred and flow into one another, as an ideological choice seems to reflect the informal and dissolutive character of contemporary socio-technical-scientific knowledge, which is the informal character of the liquid society and its non-places.

Yet, a learning space should not content itself with reproducing the status quo by becoming a mere description of the present. Architectural language does not merely transcribe the existing world but, like other artistic languages, produces it via the language itself (Pezzetti 2010, 2015).

The type linked to an architectural theme provides a structuring principle to which the spatial organisation of the parts and the identification of the various space-units that make up the school layout are subordinates, expressing a sense of unity, identity and construction for the community.

Holistic learning is based on the integration of knowledge and disciplines, not on their dissolution. Instead of dissolving the architectural space into modular, undifferentiated or blurred environments, a true integration of knowledge and creativity involves the ability to experiment on new types and their articulation in space-places, each devoted to proposing centres of attention through spatial themes, in a dialectic balance between individual freedom and a sense of belonging to the community.

The place where learning is developed jointly because of relationships with others is much more than the environment made up generically of open classrooms, workshops, shapes, colours, furnishings, yards and gardens. The school building is the first place where the learner experiences an architectural space that has the analogy and complexity of a small city and landscape, in its full richness of space-places, meanings and symbols, metaphors and metonymies attributed to forms; in the play of

\footnotetext{
${ }^{8}$ The reflection of M. McLuhan, in The Medium is the Message (1967), grasped early effects of the pervasive technological medium on the collective imagination regardless of the contents of the information conveyed.
} 
different scales, heights and layouts which predispose and stimulate different kinds of behaviour; and in the expression of tactile and aesthetic-perceptive values.

A space rich in educational space-places can stimulate active learning, thus allowing students to pick and choose what captures their attention. Children are guided by what they see and by gaining experience of differentiated spatial units or strolling through the school via a sort of architectural pedagogical promenade they discover the possibilities of relations or learning offered to them.

Learning architecture and active education can therefore learn from museums, fostering the arrangement of building in multiple space-places, tasked with proposing as many possible centres of attention and stimulating emotional and aesthetic qualities.

In association with the classroom, conceived as a home base providing a feeling of identity, social spaces, informal gathering spaces, and single or group workspaces can form a continuous fabric made of different depths of field and heights, degrees of partition and sharing; rooms, habitable recesses, squares or multifunctional theatres; shaded patios, ramps and paths; and gardens. Those spaces also serve the school as a community centre, already emphasised by the Italian experience of schools related to typological criticism (Tafuri 1968), namely in the projects by Aymonino at Pesaro and Canella in the Milan hinterland.

They support the aesthetic emotion of knowledge and are necessary for the school to work as a community centre as well.

We build as we dwell, and reciprocally "only if we are capable of dwelling, can we build" (Heidegger 1951). Architecture as the third teacher, therefore, always plays a decisive role in influencing attention, learning, development and the initiation into the aesthetic and knowledge experience.

Architecture is the art of slowness and permanence. Design innovation and the ordering of space should never depend on any specific view on education, which is just a starting point for design. Architects should instead explore spatial conditions that favour and widen the possibilities for learning within a general framework that is flexible enough to respond to continuous changes in educational pathways (Hertzberger 2008) while being characterised around durable themes and spaces.

Significantly, the UK's BSF programme launched in 2003, aiming for high-quality school design, ${ }^{9}$ commissioned by a number of pilot projects to a number of architectural firms selected expressly because they did not specialise in school buildings, asking them to rethink educational architecture from its fundamentals (DfES 2004).

There is a need and potential urge for a more in-depth fertile interaction between educational theories and architectural space.

The design of "open-air schools" between the 1920s and 1960s, Van Eyck's multifunction halls and Sharoun's learning streets, Jacobsen's morphologies and Quaroni's urban and mix-use composition, Canella and Rossi's typological montages, up to the latest prototypes by Equipo Mazzanti in Colombia, just to quote a few, turns

\footnotetext{
${ }^{9}$ Before 2011's cuts, the BSF programme involved the construction of around 706 of over 1400 of the new schools planned.
} 
the simple transcription of transient educational theories into architectural themes and a quest for spatial resources (Pezzetti 2012a, b, 2016).

Louis Kahn's metaphor of the "school before school"-a group of people sitting under a tree, intent on exchanging their knowledge without even knowing that they are, respectively, teacher and students-leads the relationship between form and design to the need to rethink not only the building but even before that the institution, right from its statutes and founding principles (Kahn 1961a).

The spatial arrangement of a work of architecture does not in fact originate from the functional programme, which rarely includes the "problem", that is, the translation into spaces of a given institution's "will of being". Architecture is exactly what is lacking in the programme but which the architect offers to the aspirations of mankind:

This is why I think it so important that the architect never follows the program given but simply uses it as a point of departure in terms of quantity, never of quality. For the very reason that the program is not architecture, it is simply an indication, like a prescription for the pharmacist. Because in the program, when it says atrium the architect must transform this into a place for entering. The corridors must become galleries. The budgets must become economies and the areas spaces (Kahn 1961b).

Moreover, as Ernesto N. Rogers stated (Rogers et al. 1965):

The matter is to activate the concept of utopia: to think pragmatically of a better society $[\ldots]$ There is no better place than the school to deal with such an issue [...] If you think how necessary it is to forge the tools to overcome the difficulties of the world rather than to comply with the current conditions - with the illusion of a guarantee-, we must not only accept but also promote the use of criticism and imagination. Which are the cornerstones of architectural research.

The school, as the public building par excellence, must aspire to be a learning urban architecture.

\section{References}

Bannister D (2017) Guidelines on exploring and adapting learning spaces in schools. Bruxelles: European Schoolnet. http://www.indire.it/wp-content/uploads/2018/04/Learning_spaces_ guidelines_ENG.pdf. Accessed June 2018

De Maio A (2011) L'innovazione vincente. Brioschi Editore, Milan

Department for Education and Skills (DfES) (2004) Exemplar designs, concepts and ideas. Department for Education and Skills, London

Drucker PF (1968) In the age of discontinuity. Harper e Row, New York

Drucker PF (1997) From capitalism to knowledge society. In: Neef D (ed) The knowledge economy. Butterworth-Heinemann, Boston

Dudek M (2000) Architecture of schools: the new learning environments. Architectural Press, Oxford

Dvir R, Pasher E (2004) Innovation engines for knowledge cities: an innovation ecology perspective. J Knowl Manag 8(5):16-27

Edwards C, Gandini L, Forman G (2011) The hundred languages of children: the Reggio Emilia experience in transformation. Praeger, Santa Monica 
Florida R (2002) The rise of the creative class. Basic Books, New York

Gandini L, Gambetti A (1997) An inclusive system based on cooperation: the schools for young children in Reggio Emilia, Italy. New Directions for School Leadership (3)

Hall P (2010) Hard policy instruments and urban development. Bartlett School of Architecture and Planning-University College London, London

Harvey D (1988) Time-space and the postmodern condition. In: The condition of postmodernity: an enquiry into the origins of cultural change. Basil Black Well, Oxford

Heidegger M (1976) Costruire, Abitare, Pensare (1951). In: Gianni V (ed) Saggi e discorsi (tran: Gianni V). Mursia, Milan

Hertzberger H (2008) Space and learning: lessons in architecture. 010 Publisher, Rotterdam

Kahn LI (1991a) Form and design (1961). In: Latour A (ed) Louis I. Kahn: writings, lectures, interview. Rizzoli International, New York

Kahn LI (1991b) Statements on architecture (1961). In: Latour A (ed) Louis I. Kahn: writings, lectures, interview. Rizzoli International, New York

Koolhaas R (1994) Construire la ville à partir des infrastructures, entretien avec Rem Koolhaas. In: L'Architecture interieure créé. Histoire et enjeux urbains, Monographic number (262)

MIUR (2013). Nuove line guida per l'edilizia scolastica. http://hubmiur.pubblica.istruzione.it/web/ ministero/cs110413. Accessed Dec 2014

Pezzetti LA (2010) Architettura senza composizione? (Architecture without composition?). A.C. (3), Pezzetti LA, Canella R, (eds) Architettura/composizione, Monographic number, pp 3-4

Pezzetti LA (2012a) Architetture per la scuola. Impianto, forma, idea (Architectures for Schools. Lay-out, Form, Idea). CLEAN, Naples

Pezzetti LA (2012b) Knowledge Hubs: la questione urbana. Città Europee e città cinesi. In: Corradi V, Tacchi EM (eds) Nuove società urbane. Trasformazioni della città tra Europa e Asia. FrancoAngeli, Milan

Pezzetti LA (2015) Architettura educatrice. Ideologia del reale o utopia della realtà? (Learning Architecture. Ideology of Reality or Utopia of Reality). In: Canella G, Manganaro E, Locatelli L (eds) Per una architettura realista. Maggioli Editore, Milan

Pezzetti LA (2016) Storia e progetto dell'edificio scolastico. Architettura educatrice nella città della conoscenza. In: Poli C (ed) Rivoluzione scuola. Valori, spazi, metodi. Overview Editore, Padua

O'Donnell WP, Peterson BM et al (2010) The third teacher. Abrams Books, New York

Rogers EN (1947) Architettura educatrice. Domus-La Casa dell'uomo, No 220, June

Rogers EN (1953-54) L'Italia è assente. Casabella-Continuità (199)

Rogers EN et al (1965) L'utopia della realtà: un esperimento didattico sulla tipologia della scuola primaria. Leonardo da Vinci, Bari

Tafuri M (1968) Teorie e storia dell'architettura. Laterza, Bari

Van Winden W (2010) Urban Hotspot 2.0: The challenge of integrating knowledge hubs in the city. http://www.urbact.eu. Accessed Dec 2011

Yigitcanlar T (2007) The making of urban spaces for the knowledge economy: global practices. In: Proceedings of the 2nd international symposium on knowledge cities: future of cities in the knowledge economy, Malaysia, pp 73-97

Yigitcanlar T, Velibeyoglu K, Baum S (eds) (2008) Knowledge-based urban development: planning and applications in the information era. IGI Global, New York 
Open Access This chapter is licensed under the terms of the Creative Commons Attribution 4.0 International License (http://creativecommons.org/licenses/by/4.0/), which permits use, sharing, adaptation, distribution and reproduction in any medium or format, as long as you give appropriate credit to the original author(s) and the source, provide a link to the Creative Commons license and indicate if changes were made.

The images or other third party material in this chapter are included in the chapter's Creative Commons license, unless indicated otherwise in a credit line to the material. If material is not included in the chapter's Creative Commons license and your intended use is not permitted by statutory regulation or exceeds the permitted use, you will need to obtain permission directly from the copyright holder.

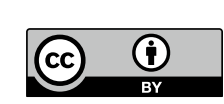

